\title{
Method, LOINC Axis 6
}

National Cancer Institute

\section{Source}

National Cancer Institute. Method, LOINC Axis 6. NCI Thesaurus. Code C40570.

The process by which an observation value was obtained. Example methods include:

weighing, use of a mass spectrometer, use of an ion sensitive electrode, and examination using a microscope. 